\title{
Counter-storytelling Across Varying Youth Contexts and Intergenerational Work in YPAR Settings
}

\section{Youth:}

Julliette Gonzales, Leilani Gomez, Jocelynne Farfan, Jose Flores, Elizabeth Ortiz, Shukri Mahamud, Nevaeh Goodman, and Nancy Hechavarias, Young Aspiring Americans for Social and Political Activism (YAASPA)

Malika Davis, Karla Torres, Saja Ibrahim, and Vijay Williams, Bringing Awareness to Racism in Education (BARE)

\section{Adult Researchers:}

Janiece Mackey, Julio Cammarota, Jihee Yoon, and Ricardo Martinez

Janiece Mackey is a race scholar activist who earned her $\mathrm{PhD}$ in Higher Education with emphases in Public Policy and Curriculum and Instruction. Janiece is co-founder and executive director of Young Aspiring Americans for Social and Political Activism (YAASPA) and postdoctoral researcher with the Equitable Futures Innovation Network.

Julio Cammarota is Professor of Education in the Teaching, Learning and Sociocultural Studies Department at University of Arizona.

Jihee Yoon is a doctoral student in the Department of Teaching, Learning and Sociocultural Studies at the University of Arizona. Her research and passion has been focused on centering youth of color through Youth Participatory Action Research and Ethnic Studies pedagogy. She first found her love of teaching and sharing knowledge with youth through her involvement in a non-profit organization, Young Aspiring Americans for Social and Political Activism (YAASPA), as well as teaching for CU Denver in the Ethnic Studies Department.

Ricardo Martinez is Assistant Professor of Learning and Teacher Education in the Department of Teaching at the University of Nebraska-Lincoln. His work is situated in Critical Youth Math Studies.

Julliette Gonzales, Leilani Gomez, Jocelynne Farfan, Jose Flores, Elizabeth Ortiz, Shukri Mahamud, Nevaeh Goodman, and Nancy Hechavarias are YAASPA alumni.

Malika Davis, Karla Torres, Saja Ibrahim, and Vijay Williams are BARE alumni.

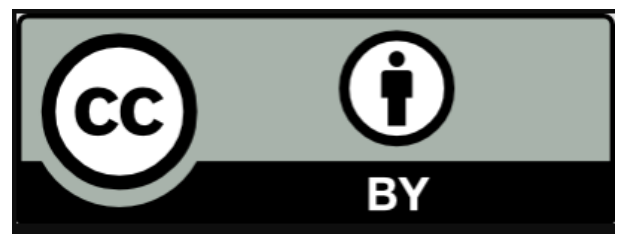

See: creativecommons.org/licenses/by/4.0/ 


\begin{abstract}
This article underscores healthy tensions of navigating youth participatory action research (YPAR) and writing in an academic and intergenerational context. Counter-storytelling (Solórzano \& Yosso 2002) is used as a method to unveil parallels across two different geographic contexts. Echoing the words of Gloria E. Anzaldúa, while we may be scared to write, we are more scared of not writing (Anzaldúa, 1981). This paper unveils experiences of displacement across two different geographic contexts among high school youth and the tensions embedded in the writing process across an intergenerational collective. In the words of Mr. Gar from $O K$ K.O.!: Let's be heroes: "sometimes it is the things we are ashamed of that are worth being proud of." Thus, we begin by revealing what it means to write as youth, as adults afraid to write for the youth. It is here in this space that we, an intergenerational collective, make the choice to write together.
\end{abstract}

Keywords: youth participatory action research, intergenerational, counter-storytelling, displacement in schools, ageism 


\section{Counter-storytelling Across Varying Youth Contexts and Intergenerational Work in YPAR Settings}

Julliette Gonzales, Leilani Gomez, Jocelynne Farfan, Jose Flores, Elizabeth Ortiz, Shukri Mahamud, Nevaeh Goodman, and Nancy Hechavarias, Young Aspiring Americans for Social and Political Activism (YAASPA)

Malika Davis, Karla Torres, Saja Ibrahim, and Vijay Williams, Bringing Awareness to Racism in Education (BARE)

Adult Researchers:

Janiece Mackey, Julio Cammarota, Jihee Yoon, and Ricardo Martinez

This paper is written by two groups that came together to form a larger collective. This intergenerational group was brought together by our engagement in the 2018 URBAN Conference which focused on building bridges between academia and community. The collective is comprised of youth and adult authors across varying levels of education from high school through doctoral education. Our academic training and socialization impacted the tensions and joys we navigated in writing together. YAASPA is a community organization based in Colorado that works with middle school through college aged youth to cultivate them to be civically engaged in community and career. YAASPA focuses on the areas of academic and career efficacy, civic literacy, civic engagement, and racial identity development. These areas are centered in YAASPA's programs and issue work led by students. In the words of Jose, YAASPA is a "nonprofit that helps connect youth to different project[s] and allows them to get involved with social justice issues and issues that affect our communities." YAASPA youth authors in this paper come from Aurora, a city that is home to more than 150 languages and many different races and ethnicities. They attend a high school in an area that has been positioned as a lower socioeconomic community full of pride and cultural capital (Yosso, 2005). YAASPA met with an adult researcher, Jihee, every other week.

BARE, based in Iowa, is a collective that emerged while engaging in the lifework known as youth participatory action research (YPAR). The BARE youth define YPAR as "a place where I can talk about racism without being ridiculed" (Karla Torres, BARE Youth); "YPAR is a place to experience other people'[s] opinions on other race related topics" (Vijay, BARE Youth); YPAR focuses on "Empowering youth to use their voices in order to create change politically regarding racial inequality, on a local, national, and global level" (Malikam, BARE Youth); and "YPAR for me is not just talking about the problem but taking action" (Saja, BARE Youth). After presenting at the URBAN Conference (see Jefferson \& Kirshner, this issue) and meeting YAASPA, these four youths constructed the name BARE. BARE represents the continual commitment to changing the world and self that began with YPAR. As the youth would say, their "adults" are Ricardo Martinez and Julio Cammarota. BARE meets weekly at school and monthly at the local public library. BARE represents the continual commitment to changing the world and self that began with YPAR.

So, what does it mean to be a high school student whose voice will appear in an academic journal? Where are the authors? I (Vijay) think it means to put yourself out there in a written form, so then people can then look up to you in some kind of way. We are academics. It is putting yourself out there in a more respectable way instead of like Twitter. Twitter can be a source of knowledge, but it depends. Twitter can be highly emotional and super reactionary when not given enough time to think about stuff unless people stop to think. There are good 
threads on Twitter where people are not just trying to bash other people. Inherently even if it has a lot of sources people will see it is not true. Compared to being in an educational journal where there are more opportunities for people to believe it or like a book where certain people will see it because specific people are going to be looking for a certain book. Additionally, we want people who grew up in middle class suburban areas that choose to isolate themselves to read this paper with an open mind, and we especially want to listen anyone who thinks that teenagers literally have nothing important to say about any topic. To the academics reading this asking about data I (Karla) say, "source? ... source? My life." Many people will ask about sources when we share our lives, a life that has lived through this, not just studied it.

We as non-youth authors of this paper struggled with the difference in what does it mean to write with/for youth versus writing about youth? To write about youth can be viewed as a violation against their agency in being producers of knowledge. Writing with youth presents a humanizing unity amongst the researchers and the researched. Within our collective work, the youth were doing research and do have the ability to speak for themselves; thus, it was necessary for the youth and non-youth to be viewed as equals. We (non-youth) want to acknowledge that at times, we are still speaking for the youth. Writing for youth can also be a misrepresentation of their lived experiences if the writing is done without guiding principles or critical reflection when making assumptions. Research done within the life work of YPAR provides an example of how writing for youth can mitigate the tensions of writing about youth (see PAR EntreMundos: A Pedagogy of the Américas, Ayala et al., 2018 and/or Youth Resistance Research and Theories of Change, Tuck, 2013).

YPAR allowed the non-youth authors to center the narratives and experiences of students as an invaluable expertise. Intergenerational voice is crucial within YPAR work as knowledge is shared within a collective space with youth, adult researchers and beyond. Rather than coming up with themes for the students, we as adults engaged in inquiry alongside the students to position them as the innovators of the themes and narratives shared in this article. The tensions of power and privilege still exist within YPAR work as adult researchers have the power to write for and about youth research and present at conferences, often leaving the youth behind. Working across geographies and intergenerational contexts allowed for collaborative learning and themes to be co-developed in ways that speak to and honor the experiences of youth. Thus, when we write, it is representative of all of us. The non-youth acknowledge that at times they are writing about youth, but the non-youth are also writing about and with youth. More so, youth have oversight over all narratives shared and in being part of the revision-submission process for publication. Therefore, within our article, we challenge that relationship by writing as a collective. We write as a collective "us."

\section{Displacement}

"Displacement to me means being removed or taken away from an Identity or position."

"Displacement in school to me means not having the ability or access to have a say in educational decisions about us the students. It also means not being able to have discussions about inequities that affect us in our community because the adults in our school don't want to have those type of discussions." 
"Students being forced to not only conform and adapt to a society in which wants them to be something they are not, but also being ignored and having the fear of not being enough or less than."

The above quotes emerged when we (non-youth adults) anonymously asked the youth to address the question, "What does displacement in your school mean to you?" These quotes will act simultaneously as our anchor and as a reminder to the reader to honor the voice and knowledge created by youth. As the second quote hinted, displacement occurs both in and outside of school and is linked to inequity. Displacement can happen in an array of ways from gentrification to miseducation to having to sit in the back of the class. BARE and YAASPA met at the URBAN Conference in 2018 and came together to grapple with ways they have been displaced in their schooling experiences from two different states: Colorado and Iowa. The youth come from two different schooling contexts that represent differences in compositional diversity and socioeconomic status. However, there were commonalities in sentiments concerning displacement around issues of identity in their schooling experiences. Youth envisioned a desire to push back against deficit narratives concerning race and class (Gillborn, 2010) imposed upon them in their schooling experiences. With a grounding of Critical Race Theory, particularly counter-stories (Solórzano \& Yosso, 2002), BARE and YAASPA brought their narratives together to work toward exhibiting their linguistic capital (Yosso, 2005) via formative development of a podcast. Youth share in dialogue around the theme of displacement for the purpose of a healing praxis (hooks, 1994), but also "critical hope [which] also requires that we must be painfully honest about the realities of current educational conditions... while at the same time building networks that challenge these conditions" (Stovall, 2013, p. 34).

\section{Context Story of BARE and YAASPA}

The connection between BARE and YAASPA began at the first URBAN conference when the youth had an opportunity to be paired for a workshop on their research actions. After the youth shared space together, the synergy was organic and they desired to continue their relationship. With a second iteration of the URBAN conference, Julio and Janiece connected on this being another opportunity for the youth to bridge their intellectual and research interests together. After arrangements were made by Janiece and Julio, communication continued between Jihee and Ricardo to set up the school visit, where both worked to prepare youth to meet each other. During the visit, BARE youth were able to sit in on select classes to shadow YAASPA youth. After a class observation, YAASPA youth led BARE youth on a complete tour of the school. This classroom meeting was set up so youth could know who they would be presenting with later at the conference. I (Saja) recall,

Meeting YAASPA for the first time was a pretty awkward interaction, although we had similar thoughts and ideas it was filled with a quiet silence. I remember us (BARE) asking them questions and there was an awkward pause before someone answered. It felt like an interview instead of a friendly conversation. YAASPA was so kind to us, giving us smiles and everything, but as teenagers we became introverts, just as when we meet anyone new. We did not have many discussions outside of our work, but the second time meeting with each other things changed. 
The second meeting occurred during the URBAN Conference follow up. Here, the displacement was felt due to being situated in a traditional academic setting in which the space and time created for the youth was experienced as reduced. The conference provided room and board at a hotel and it was this space outside of the conference time that allowed for youth to strengthen their bonds. As I (Karla) put it:

Meeting someone can be pretty weird. I've met plenty of people in strange circumstances. Sometimes some of the more stranger circumstances have yielded some of my closest friends. I know for a fact that you can't put people together for a while and assume that they'll become best friends. School is an excellent example of that.

Being (and presenting!!) in Denver was where I made some really good friends, friends that I think I'll be able to keep for a lifetime. Though, when I first met them, that wasn't really what I was thinking. What was really going through my head was: "This is really awkward. I really don't know what to say," and honestly, I think that's okay.

These reflections, echo Saja's sentiment about the second meeting with YAASPA:

We became more comfortable with each other, our work became stronger and so did we together. It was at that moment when we had a little party, and we played some music, had pizza, and begun to talk to each other. We learned some deep secrets and finally became vulnerable to one another. Everyone shared a life experience about them, good or bad, and it was a very meaningful moment for us. (YAASPA \& BARE)

The trust and the bond we had become something more than anything I ever imagined. Leaving the first time was like "okay bye," but the second time was full with hugs, laughter, and photos we can remember. At that moment I shed a tear as I was so grateful to have met amazing, phenomenal, and talented people. I'm so grateful that I can now call them a friend.

As the youth processed their encounters and the journey of their friendship, we can see how YAASPA's youth too mirrored many of the vulnerabilities and powerful connections they made with BARE youth. I (Leilani) recall:

My first time meeting the students from BARE was honestly very scary for me. Not so much the thought of meeting them, just being in the moment was something intimidating. The way they presented themselves and spoke with such eloquence was completely different than the way my friends and I spoke and acted with each other. I constantly had to remind myself that they, too, were people. Coming from the hood in LA and moving to the hood of Aurora, I didn't hear or see people like them every day. Looking back at it, I feel so bad. After meeting them and spending the weekend with them, I learned that we're honestly not that different at all. I completely forgot that we all met up for the same reason. We were all students of color who were constantly noticing the wrongs around us 
and constantly going through displacement. We grew especially close after presenting at the URBAN Conference and talked about how we were displaced during the feedback portion of our presentation together.

Having all of us present together made me feel more confident since there was others to validate my feelings and make me feel like what I was feeling wasn't wrong. We all felt similar feelings and opinions building up inside of us after someone told us we needed facts and data to be talking about what it's like to be us. Even though BARE comes from Iowa and my YAASPA buddies are from Colorado, it made me realize, it doesn't matter where you come from or what it sounds like when you talk in person. If there's someone who has more power than you in society with a certain identity, you'll feel it. The fact is, we're young students of color getting feedback from old, White people. It's almost inevitable for them to not understand where we were coming from. We're constantly told, "It can't be that bad," or "Are you sure?" This is something that all students like us have heard before when telling our stories. No matter what they sound like, where they live, or how they present themselves. I had trouble with that and always used to feel like I was in the wrong and always agreed with those old, White people. Being with BARE and hearing them speak out about how they also felt displaced made me more certain of what I was feeling and more confident with my thoughts. They have helped me to not be afraid of pointing out the wrongs I see and experience no matter what the feedback and reaction may be. For this, I'm very thankful for BARE and my YAASPA buddies.

Last, Julliette expresses the impact the meeting between BARE and YAASPA has been for her:

Meeting BARE and the URBAN Conference was an experience I will forever be grateful for. We were two groups of kids from two opposite communities with the same issues. We had similar experiences when dealing with situations such as displacement in our education, communities, and even professional spaces like the conference. We collectively had different identities, but we came together to expose those inequalities and it made us stronger as a group.

\section{Youth Defining Displacement}

Academic articles often situate the naming and defining of phenomena in conversations that are often inaccessible to those who are most impacted by the phenomena. Rather than ground the naming and defining of displacement in the context of the literature, we choose to ground the definition of displacement through the lens of youth researchers (YAASPA and BARE). We use the organizing principle that those most impacted should be the ones to define and lead. With this in mind, the adult authors are taking the lead of youth by honoring their intellectual labor in defining displacement. Honoring their intellectual capacity and labor is also in alignment with YPAR, which situates youth as experts. Furthermore, we do not want to use literature to displace their intellectual contributions to the field.

YAASPA and BARE began their work by addressing the questions, "What does displacement in your school mean to you?" and "If you have an example of displacement at your school please share that example(s) below." The questions were anonymously answered on a shared Google forum which allowed both groups to view what each other stated, but they could not see what a given individual wrote. Table 1 below shows how some youth responded. 


\section{Table 1}

\section{Displacement Defined by Youth through Examples}

\section{What does displacement in your school mean to you? \\ If you have an example of displacement at your school please share that example(s) below.}

Not getting treated the same ways as others

Displacement in my school means feeling like you are not good enough because of your race, not have equal rights, being told you are to[o] young to be an advocate. It means being treated like you are dumb because you are not on the same "level" as someone else.
An example of displacement at my school is when my peers and I are left out of school funding meetings. We are supposed to know where that money goes but since we are kids/students they don't include us in them.

An example of displacement in my school would be when our parents are invited to parent [conferences] to discuss with our teachers about our school and yet we don't get an invitation.
Not being able to share my opinions and personal narratives in a space that is supposed to be for the youth but teachers are the ones who get to share their opinions and we have to agree with them. The rights to an opinion are displaced.

Displacement in school means not getting the same opportunities because of language barriers.
The Extended Learning Program (ELP) at my school as a whole as there is a large absence of African American students in that class unless they were brought in thank[s] to their parents intervention (at least that was how I got into ELP). You can find large portions of the African American community at Ames High School in the "easier" classes when it comes to the big three classes of Math, History, and Science.
To be put in a corner where I don't belong just being pushed somewhere because my potential and success is not seen by the "powerful" people who can help increase it.
Even though my school has a heavy latino/hispanic population, there are still a lot of asian and african refugees at our school. So, when meetings and programs are only offered in english and/or spanish, it leaves the rest of my community out.

In Table 1, each young person anonymously answered the above question, providing an example of displacement before all responses were shared with youth as a group. Both groups independently reviewed and discussed responses to the question before coming together to analyze and identify emerging themes. It was decided to focus on two forms of equity displacement; the first is centered on displacement that results between the difference of schooling and education, and the second revolves around the displacement of identity and culture 
within schools. In order to address issues of displacement, the youth decided to create a podcast to unravel inequities brought upon them due to displacement. The podcast was in the formative stages of development but dissipated over time due to shifts and transitions the research team (youth and adult partners) experienced.

\section{Theoretical Framing of Counter-stories}

Often the narratives and voices of youth can be silenced due to the notion that they "lack" experience with life. But youth are not short of experience concerning the inequities and hidden curriculum they experience in their schooling. Youth are, and should be, centered as the experts of schooling because they are the "customers" experiencing every facet of education from flows of funding, educators, counselors, coursework, and the policies imposed on them despite not having voting power. However, the convergence of the lived experiences of youth shared collectively depicts the power of counter-storytelling as a tool for healing, building collective consciousness, and educational change. Yosso (2005) suggests that counter-storytelling:

...is also a tool for exposing, analyzing, and challenging the majoritarian stories of racial privilege. Counter-stories can shatter complacency, challenge the dominant discourse on race, and further the struggle for racial reform...these experiences can help strengthen traditions of social, political, and cultural survival and resistance" (p. 32).

As the counter-stories of Black and Brown youth collided, they quickly noticed the saliency of how their racialized experiences inform their schooling experiences despite schooling contexts of varying socio-economic statuses. The following table depicts the themes developed alongside the counter-stories illustrated by our youth authors.

\section{Table 2}

Themes Alongside Youth Counter-stories

\section{Youth Author(s) Counter-stories}

Jose

Vijay

Jocelynne

Leilani

Julliette

Saja

\section{Themes}

Theme 1: Intersections of Identity Affecting my Schooling Experiences

Theme 2: Displacement across Geographic Contexts

Theme 3: The Role of the Educator Verbalized 


\section{Counter-stories}

Youth discussed the banking method of education (Freire, 2018), institutionalized racism (Jones, 2002), and whiteness (Leonardo, 2002) as threads that showed up within their counterstories. The counter-stories were not shifted or reworded in order to honor the voices and authorship of BARE and YAASPA youth. The counter-stories were developed among the youth authors as a way to support the development of their future podcast and to show synergy amidst their different schooling contexts.

\section{Theme 1: Intersections of Identity Affects My Schooling Experiences}

I, Jose (YAASPA Youth), remember, "Throughout my high school experience I felt many things, one of which I felt displaced. This happened in many forms because of my various identities. One example of how I was displaced academically was how teachers and administrators would continually make decisions about my education without fully knowing me or my learning style. This impacted my classes and schedule in many negative ways. In addition, I was also displaced being a male in a dominantly female sport. Being in Poms constantly allowed teachers and other students to constantly ask inappropriate questions and treat me differently. This one identity became all I was, and I soon became nothing more. I was no longer a student or a man, instead I was just this kid on a dance team. This only began to happen my senior year of high school, but before that I was being displaced as a Latino. All throughout high school I was told that I wasn't allowed to speak my native tongue of Spanish as "this is America where we only speak English." I never really felt comfortable speaking Spanish at school after that, and it made me lose a piece of my culture."

\section{Theme 2: Gentrification Across Different Geographic Contexts as Displacement}

I, Vijay, (BARE Youth) remember, "My experience in Denver, Colorado brightened my eyes to the scope of a city undergoing gentrification. I currently live in Ames, Iowa with my parents which lies outside of the city of Des Moines. While Ames itself is labeled as 'The City of Ames,' it is really just a small college town with not a single skyscraper in sight. Our town is small enough where you can live in one part of it and not have any real reason to leave your neighborhood as you most likely have some kind of way to get the essentials in life near your house. In fact, most people that live in Iowa have not yet left for generations in their family, to me that's kind of sad. I moved to Ames, Iowa when I was seven years old from the real city of Atlanta, Georgia. Being seven at the time of the move, my only thought about the change was that there was a lot less traffic and a lot less to do in Ames, Iowa. The lack of things to do in Ames is something that has gripped not only outsiders but also the people that live inside of Ames, but for some reason people still remain here their whole lives. Lack of things to do is one of the reasons why my family members who aren't immediate don't visit that often.

When I went to Denver with the rest of the BARE group, I got to experience something that was like midway between my home in Atlanta and my home in Ames. While there still was some traffic, it wasn't as bad in Denver, and while there was a lot of city it wasn't that hard to find the suburbs. One of the biggest gripes I had about Denver was the fact that when you left the city and went into the more suburban areas you could see the gentrification happening around you. Heck, even in the city itself you could find small apartments being remodeled into modern apartment complexes for the rich. One of the things that made me happy about Denver was the fact that you didn't have to travel too far to find something new to do. When it came to food places the only real chain restaurant you would find is a Popeye's Chicken every so often in the 
suburbs. In Ames you only have all the main chain fast food restaurants with McDonald's here, a Chick-Fil-A there, and a Burger King and Wendy's everywhere else. Whenever we traveled in Denver for the URBAN Conference I would notice that it was usually better to walk than drive to traffic and harder to find a good place to park for cheap. I think I really enjoyed being able to walk everywhere which is why I wish Ames was more walking accessible. Ames may be a small town, but overall everything is spread apart. I think when it comes to the schooling areas everyone seems pretty close to the schools in the suburbs with not a single kid (that I could tell) living in the city. I think here in Ames there is a disconnect between those who live close to schools, those who live in apartment suburbs, small house suburbs, and rich people suburbs. All in all, if I had the ability I would want to merge Ames and Denver in order to be a space where you can have peace but also have tons of fun in the city."

\section{Theme 3: The Role of the Educator}

I, Jocelynne (YAASPA Youth), have come to understand, "At our school, it is difficult to start discussions on issues that are facing the school community. At school, there is a culture that discourages students from speaking about important social and political issues. There are some students that make light of sparking conservation. When a person does try to start discussion, it usually ends with jokes. I think students need to be encouraged to speak their minds without fear of being judged. There are also times when students feel as if they are not being involved with decisions made at school about them. There was a time where many teachers left the school and the students were vaguely informed why. Adding to not really knowing why many teachers have left, we have heard of some teachers from themselves that they have not been treated right and that makes them leave, which affects us because we don't have that teacher that we have a strong bond with us that is supposed to help us get through high school and prepare us. Another thing is that we students are also left out of things like parent coffee meetings, where they talk about things that involve us and our education."

I, Leilani (YAASPA Youth) reflect, "Our school gets a lot of White teachers that we can tell don't know how to act around us. It really prevents us from making connections with teachers because sometimes they either try too hard to be "like us" or are really closed minded to accepting our cultures. You can tell seeing so many people of color at once almost makes them nervous and can sometimes even get in the way of their teaching job. They show this a lot when they try to make up for being White and always say "because I'm White" which also makes things awkward."

\section{Theme 4: The Way Displacement is Felt and Verbalized-We Need Learning Communities to Navigate Feelings of Displacement}

I, Julliette (YAASPA Youth), have come to learn, "At my school, my education was valued but at a very expensive cost. It was to the point where I wasn't included in my learning experiences. Important and influential choices were being made for me without an idea of what was best for me. At work I was exposed to sexual harassment, and I finally understood how it became so normal for women to stay quiet rather than speak up. I have been displaced in every professional space that I have so far encountered, and I can guarantee I, and others like me, will continue to experience the same displacement. Thankfully for YAASPA I can identify this displacement and decide where I want to invest my time. Being a student of color the inequities we experienced was never something I recognized until I moved from a very predominantly White area to a community of color. For me, it was a big culture shock as I had never been in an 
area where there were more than two people who looked like me. My sophomore year I joined YAASPA and it opened a door to many opportunities and experiences I could never imagine."

We end this section of counter-stories by offering a poem to the reader. Regarding the poem, Saja (BARE youth), "I remember the feeling crawling up my body as I wrote this poem. I held back tears as this poem conveys my reality, my truth, and truth of many others. As a person of color you grow up to realize the unfairness, the injustice, and the hatred of your skin. You are left confused with a cloud of sadness above your head as you wonder, "why?"

\section{Poem Titled: $\underline{\text { Save Me }}$}

When the cards are all against me.

I feel like I cannot ever be free.

Trapped in a world where I can't speak.

And only feel defeat.

Not noticed for my intelligence.

Instead noticed for the color of my skin.

Taken down by the others upon me.

Walking with shame, and no pride left in me.

Being glued to the word crime.

People wanting me to only do time.

The color of my skin defines me.

Being a useless utensil that I should not be.

I raise my hands and only ask.

Save me from the society that rejects me.

Save me from ever thinking of equality.

Save me from always being last no matter how hard I try.

Save me from the words that scar my heart and only do.

Save me, because I am lost and don't know what to do.

Racism only brings us down.

And we shall only rise up.

We have each other.

We will support one another.

Love and peace shall bring us together.

Fight Racism.

And we shall always be the winner.

\section{Conclusion: A Moment of Reflection}

"At the URBAN Conference, my group and I weren't viewed at the same value as the other presenters there, and it wasn't because our experiences weren't valid but because of our age. We were asked to present statistics and other evidence to back up experiences we had when nobody else there was asked the same. It just so happened to be that we (YAASPA and BARE) were the only presenters still in high school." -Julliette Gonzalez (YAASPA Youth)

Rather than writing for the students, this article is a depiction of adults taking a step back and supporting the creative genius naturally ingrained in youth. It is critical that youth not solely be given platforms to articulate their ideas, experiences, and counter-stories, but that they also 
have the opportunity to be compensated for their labor via authorship. Youth have engaged in this writing platform for themselves and their own liberation in partnership with the orchestrators of URBAN as well as adult facilitators from BARE and YAASPA. We acknowledge that there may be a healthy tension embedded in this piece devoid of citations and even causing adults to reflect upon the ways they have taken up space in ways that cramp youth exhibiting their intellectual prowess. However, this tension is necessary to shift the power dynamics that persists in youth adult partnerships.

A major learning for the adults in this process was engaging in self-reflexivity concerning our positionalities. We constantly grappled with how our positionalities impacted our engagement, facilitation, and support of youth because of acknowledging tensions that arise for us when asked to perform academically via writing, public speaking, research, etc. We had to reflect upon how these personal tensions impacted the orchestration of our engagement with the BARE and YAASPA youth and how we can re-envision and re-imagine our partnership in ways that enable youth more agency than in these past rounds of engagements. Furthermore, there is a literary tension as well in how collective writing happens in youth adult partnerships as well. Who is the "we" or "us" when writing? How do you ensure that the collective "we" does not invade the space of the youth "we"?

Lastly, there is a natural inclination to jump to coding and analyses through academic training. But, this process can be intrusive to youth authorship and youth adult writing as well, which tends to be the case with more traditional journal, particularly our coding is not done with the youth and when the lenses and frames of coding are imposed on youth counter-stories without their permission and engagement. This is why pausing, listening, and executing patience as adults is critical to youth adult writing and research. Sitting in the stillness of counter-stories and allowing for more time and engagement to occur for further analyses is central to this collaboration. Our collective reflection and grapplings do not decrease the power, prowess, nor labor of youth or non-youth adults, but instead re-iterate the power of collective consciousness and synergy. Youth agency and spaces like URBAN are necessary and vital for youth adult partnerships and for writing to be refined, deconstructed, and reconstructed.

\section{Countering Displacement}

We end by making the choice to have the last word be that of the youth. In sharing their stories together, youth from Iowa and Colorado were able to create a space where they could discuss injustices that result from displacement. In one of our video calls, we all discussed the bonds we created. In that instant, the youth created and shared with each other the following meme:

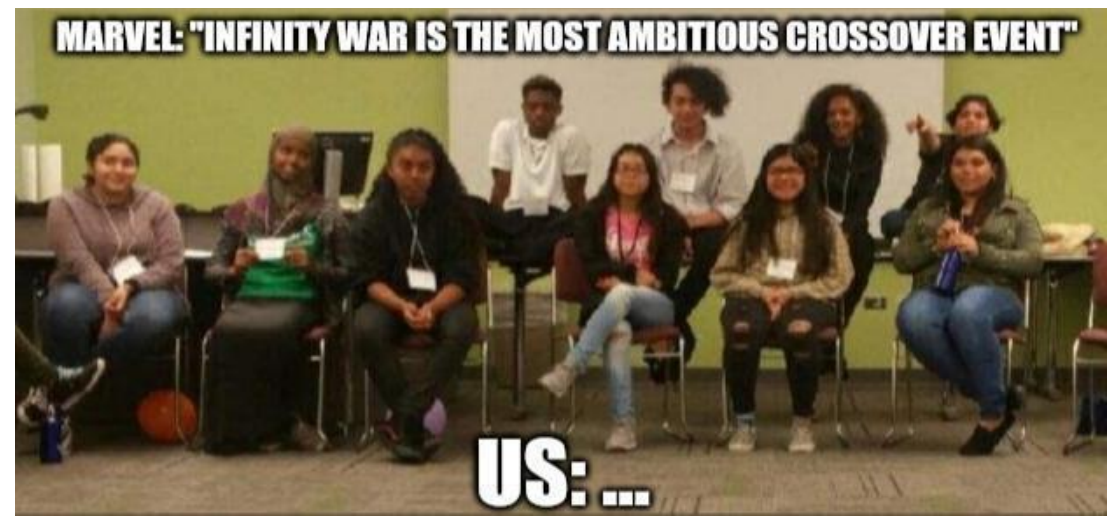


This meme is based on the popular Marvel film Avengers Infinity War. The film was a cinematic event spanning more than twenty years and represents the coming together of multiple groups working collectively for a singular cause. This meme highlights the coming together of BARE and YAASPA as a force to challenge injustice. 


\section{References}

Anzaldúa, G. (1981). Speaking in tongues: A letter to third world women writers. In C. Moraga \& G. Anzaldúa (Eds.), This bridge called my back: Writings by radical women of color, (1st ed., pp. 165-174). Persephone Press.

Ayala, J., Cammarota, J., Rivera, M., Rodriguez, L., Berta-Avila, M., \& Torre, M. E. (2018). PAR entremundos: A pedagogy of the Américas. Peter Lang Inc., Internal Academic Publishers.

Gillborn, D. (2010). The colour of numbers: surveys, statistics and deficit-thinking about race and class. Journal of Education Policy, 25(2), 253-276.

Freire, P. (2018). Pedagogy of the oppressed. Bloomsbury Publishing.

hooks, b. (1994). Teaching to transgress. Routledge.

Jones, C. P. (2002). Confronting institutionalized racism. Phylon (1960-), 7-22.

Leonardo, Z. (2002). The souls of white folk: Critical pedagogy, whiteness studies, and globalization discourse. Race ethnicity and education, 5(1), 29-50.

Solórzano, D. G., \& Yosso, T. J. (2002). Critical race methodology: Counter-storytelling as an analytical framework for education research. Qualitative Inquiry, 8(1), 23-44.

Stovall, D. (2013). Against the politics of desperation: Educational justice, critical race theory, and Chicago school reform. Critical Studies in Education, 54(1), 33-43.

Tuck, E., \& Yang, K. W. (Eds.). (2013). Youth resistance research and theories of change. Routledge.

Yosso, T. J. (2005). Whose culture has capital? A critical race theory discussion of community cultural wealth. Race Ethnicity and Education, 8(1), 69-91. 